\title{
CAPÍTULO 31: RESÍDUOS AGROINDUSTRIAIS: UMA ALTERNATIVA PROMISSORA E SUSTENTÁ VEL NA PRODUÇÃO DE ENZIMAS POR MICRORGANISMOS
}

\section{CHAPTER 31: AGRO-INDUSTRIAL WASTE: A PROMISING AND SUSTAINABLE ALTERNATIVE IN THE PRODUCTION OF ENZYMES BY MICROORGANISMS}

\author{
Viviane do Nascimento e Silva Alencar ${ }^{1}$; Juanize Matias da Silva Batista²; Thiago Pajeú Nascimento ${ }^{3}$
} Marcia Nieves Carneiro da Cunha ${ }^{4}$; Ana Cristina Lima Leite ${ }^{5}$

\section{Resumo}

Nos últimos anos, devido à maior preocupação da ciência e da sociedade pelo meio ambiente, houve um crescimento no número de pesquisas que visam a utilização dos resíduos agroindustriais como uma maneira de aproveitamento para a geração de produtos com alto valor agregado. Existem diferentes tipos de resíduos gerados pelas indústrias, como por exemplo, indústrias de curtume, sucroalcooleiras, abatedouros, criações de animais, alimentícia, celulose e papel. Os microrganismos podem ser utilizados na bioreciclagem desses resíduos ou na produção de vários produtos de alto valor agregado, incluindo biomoléculas industrialmente importantes. O baixo custo deste tipo de matéria-prima permite o desenvolvimento de processos economicamente competitivos e ecológicos. Uma das maneiras de utilização dos resíduos agroindustriais é através do processo de fermentação em estado sólido, pois a natureza físicoquímica desses substratos facilita a colonização por microrganismos. Há um grande avanço em pesquisas nesse campo, especialmente devido a solução de problemas ambientais e tentativas de redução de custos dos bioprocessos. O objetivo desse trabalho foi realizar uma breve revisão sobre a utilização de resíduos agroindustriais para a obtenção de produtos biotecnológicos de alto valor agregado e sua contribuição para sustentabilidade do planeta.

Palavras-Chave: resíduos agroindustriais; compostos bioativos; fermentação em estado sólido; microrganismos.

\begin{abstract}
In recent years, due to the greater concern of science and society for the environment, there has been an increase in the number of studies aimed at the use of agro-industrial waste as a way of using it to generate products with high added value. There are different types of waste generated by industries, such as tanneries, sugar and alcohol, slaughterhouses, raise animal, food, cellulose and paper. Microorganisms can be used in the bio-recycling of these residues or in the production of various products with high added value, including industrially important biomolecules. The low cost of this type of raw material allows the development of economically competitive and ecological processes. One of the ways of using agro-industrial residues is through the solid state fermentation process, since the physical-chemical nature of these substrates facilitates colonization by microorganisms. There is a great advance in research in

\footnotetext{
${ }^{1}$ Pós-graduação em Inovação Terapêutica, Universidade Federal de Pernambuco, viviane.ntosilva@ gmail.com

${ }^{2}$ Pós-doutorado, Universidade Federal Rural de Pernambuco, juanizematias@ yahoo.com.br

${ }^{3}$ Pós-doutorado, Universidade Federal Rural de Pernambuco, thiago_pajeu@ hotmail.com

${ }^{4}$ Pós-doutorado, Universidade Federal Rural de Pernambuco, marcianieves@ yahoo.com.br

5 Professor Departamento de Ciências Farmacêuticas, Universidade Federal de Pernambuco, acllb2003@yahoo.com.br
} 
this field, especially due to the solution of environmental problems and attempts to reduce the costs of bioprocesses. The objective of this work was to carry out a brief review on the use of agro-industrial residues to obtain biotechnological products with high added value and their contribution to the sustainability of the planet.

Keywords: agro-industry waste; bioactive compounds; solid-state fermentation; microorganisms.

\section{Introdução}

O agronegócio é um setor produtivo promissor e deve apresentar expansão de 3\% em 2020 no Brasil (MAPA, 2018). Nas contas da Confederação da Agricultura e Pecuária do Brasil, o Valor Bruto da Produção Agropecuária (VBP) será 9,8\% maior em 2020 em relação a 2019. O crescimento acentuado do agronegócio brasileiro o coloca em posição de destaque no processo de desenvolvimento do país.

A produção agropecuária de destaque do Brasil, também influencia na grande produção de resíduos. A Organização das Nações Unidas Para a Alimentação e a Agricultura (FAO), estima que a produção mundial de resíduos agroindustriais atinja 1,3 bilhão de toneladas por ano, sendo que, 1/3 dos alimentos potencialmente destinados ao consumo humano são desperdiçados, seja como resíduos, oriundos do processamento, ou como perca na cadeia produtiva (FAO, 2013).

Com isso, quantidades significativas de resíduos agroindustriais são descartadas pelas indústrias; no entanto, o aproveitamento desses resíduos se traduz em uma forma de minimizar os impactos ambientais causados pelo descarte incorreto destes no ambiente. Além disso, eles representam matérias-primas interessantes para a produção de produtos com possível valor agregado. Uma maneira para o aproveitamento desses resíduos é o bioprocessamento para a produção de produtos como biocombustíveis (etanol, butanol e hidrogênio), produtos químicos valiosos, como: ácidos orgânicos (ácido butírico, ácido succínico, ácido itacônico, ácido lático, ácido fumárico e ácido málico), triacilgliceróis, polihidroxialcanoatos, e também enzimas e outras biomoléculas (MARZO et al., 2019).

Diversas agroindústrias têm realizado o aproveitamento dos resíduos na produção de subprodutos, como na indústria de produção de queijos, utilizando o resíduo do soro lácteo na produção de bebidas fermentadas, onde também, os setores de produção animal, já utilizam o soro na incrementação de ração; indústrias sucroalcooleiras utilizam o bagaço oriundo da produção de etanol, para fornecimento de energia nos fornos industriais das usinas (COSTA FILHO et al., 2017). 
Essa valorização dos resíduos agroindustriais como suportes nutricionais para a produção de bioprodutos oferece uma alternativa de diversificação de produtos para agricultores e para a agroindústria (SCHALCHLI et al., 2016), além de atender a preocupação com a limitação de recursos fósseis, problemas ambientais e sustentabilidade, juntamente com a preferência do consumidor por produtos naturais, biodegradáveis e ambientalmente amigáveis (DIAZ; BLANDINO; CARO, 2018).

Essa preocupação global em relação à geração de resíduos, que são categorizados em industrial, agrícola, sanitário e sólidos urbanos (DIAZ; BLANDINO; CARO, 2018), impulsiona a chamada biotecnologia sustentável que estimula o desperdício zero (NNOLIM; OKOH; NWODO, 2020), uma intervenção que não apenas ajuda a combater a poluição ambiental, permitindo a restauração completa do solo orgânico e contribuindo positivamente para os esforços de minimização do aquecimento global (NAIDU; SIDDIQUI; IDRIS, 2020), mas também contribui significativamente para a economia, pois, estrategicamente, incita a utilização desses resíduos para produção de itens de alto valor (PRAKASH et al., 2018).

A maioria dos resíduos agrícolas é de natureza lignocelulósica, sendo uma grande fração composta de carboidratos, por isso os resíduos agroindustriais são altamente nutritivos por natureza, eles facilitam o crescimento microbiano e uma forma de utiliza-los é com o emprego de microrganismos e/ou de produtos microbianos com propriedades que possam ser usados na bioreciclagem e também para a produção de vários tipos de produtos de valor agregado, incluindo biomoléculas industrialmente importantes (NNOLIM; OKOH; NWODO, 2020).

As biomoléculas, produtos do metabolismo microbiano, são de alta relevância na economia verde devido a sua alta especificidade pelos substratos, maior eficiência catalítica, boa relação custo-benefício e serem eco-amigáveis (NNOLIM; OKOH; NWODO, 2020).

Resíduos agroindustriais, como bagaço de cana, espiga de milho e farelo de arroz, têm sido amplamente investigados para serem aproveitados como matéria-prima para diferentes estratégias de fermentação com vistas à produção de biomoléculas (RAVINDRAN et al., 2018).

Esses resíduos podem ser usados na fermentação em estado sólido (SSF) devido à sua fácil disponibilidade, alta biodegradabilidade e rica fonte de nutrientes como carbono, reduzindo assim a custos de produção e o impacto ambiental de sua disposição (NAIDU; SIDDIQUI; IDRIS, 2020; SADH; DUHAN; DUHAN, 2018).

Devido ao exposto, é de suma importância que se estude meios de utilizar esses recursos agroindustriais de forma eficiente. O objetivo desse trabalho foi fazer uma breve revisão sobre a utilização de resíduos agroindustriais para a obtenção de produtos 
biotecnológicos de alto valor agregado por microrganismos e sua contribuição para sustentabilidade do planeta.

\section{Desenvolvimento}

\subsection{Resíduos agroindustriais}

Os resíduos agroindustriais são gerados no processamento de alimentos, fibras, couro, madeira, produção de açúcar, álcool, etc., sendo sua produção, geralmente, sazonal, condicionada pela maturidade da cultura ou oferta da matéria-prima. As águas residuárias podem ser o resultado da lavagem do produto, escaldamento, cozimento, pasteurização, resfriamento e lavagem do equipamento de processamento e das instalações. Os resíduos sólidos são constituídos pelas sobras de processo, descartes e lixo proveniente de embalagens, lodo de sistemas de tratamento de águas residuais, além de lixo gerado no refeitório, pátio e escritório da agroindústria (COSTA FILHO et al., 2017).

Os resíduos podem ser classificados em orgânicos e inorgânicos. Os resíduos orgânicos são aqueles gerados nos setores de agricultura e pecuária como os rejeitos das culturas (café, cacau, banana, soja, milho, etc.), dejetos gerados nas criações animais e os efuentes e resíduos produzidos nas agroindústrias, como abatedouros, laticínios e graxarias. Os resíduos sólidos inorgânicos abrangem as embalagens produzidas nos segmentos de agrotóxicos, fertilizantes e insumos farmacêuticos veterinários, além dos resíduos sólidos domésticos da área rural (RODRIGUES et al., 2013).

Temos ainda os resíduos agroindustriais classificados como biomassa lignocelulósica, onde a lignocelulose é o principal componente da biomassa vegetal, composta principalmente por celulose, hemicelulose e lignina. A celulose é um polímero de homopolissacarídeos composto por D-glicose ligada por ligações $\beta$-1,4-glicosídica, organizadas nas plantas em microfibrilas cristalinas. É protegida por uma região amorfa de hemiceluloses e lignina, responsável pela estrutura recalcitrante das células vegetais. No que se refere à hemicelulose, é um heteropolímero ramificado de 93 monômeros de açúcares, como xilose, arabinose, manose, glicose e galactose (CHANDEL; SINGH, 2011; DIAZ; BLANDINO; CARO, 2018). Para usar essa biomassa como matéria-prima em processos fermentativos, a estrutura da lignocelulose deve ser previamente desconstruída por uma etapa adequada de pré-tratamento e posteriormente, hidrolisada para produzir açúcares fermentáveis, incluindo glicose, xilose, arabinose, ácido galacturônico, etc. (KUMAR; SINGH; KORSTAD, 2017; MARZO et al., 2019). 
Logo, tem-se que uma grande gama de subprodutos são gerados durante o processamento industrial dos resíduos agroindustriais. Em geral, não há nenhuma aplicação direta desses resíduos, como: caule, folhas, sementes, polpa de frutas, legumes e cereais. No entanto, esses resíduos são ricos em açucares, fibras, proteínas e minerais que são essenciais para síntese de produtos bioativos por microrganismos (PANESAR et al., 2016). A Figura 1 traz diversos exemplos desse potencial.

Figura 1 - Potencial de valorização de resíduos agroindustriais.

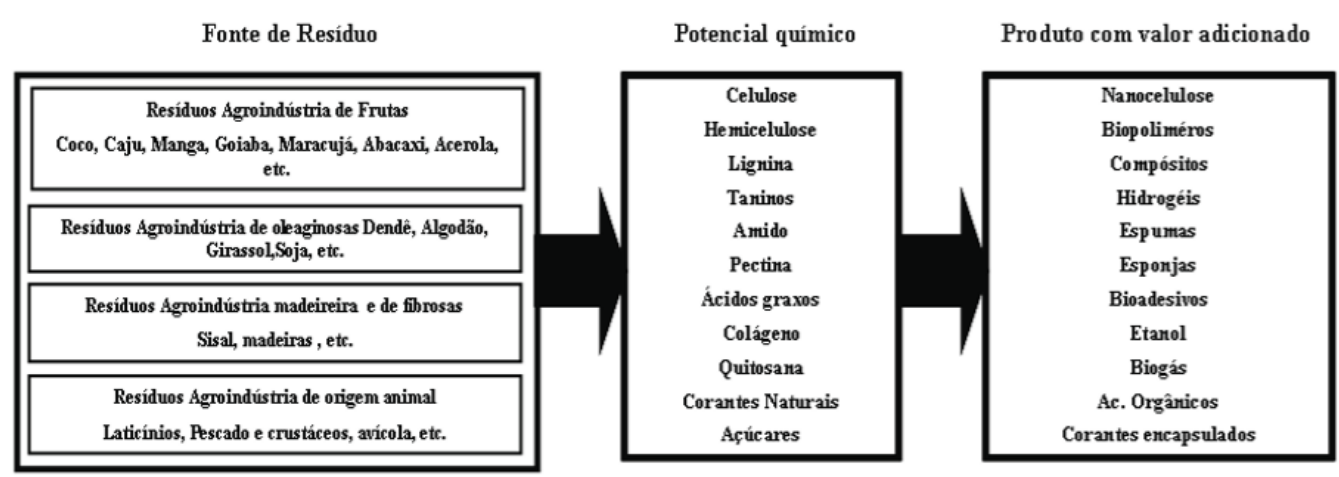

Fonte: COSTA FILHO et al., 2017.

\subsection{Pré-tratamento de resíduos agroindustriais}

O uso de resíduos agroindustriais renováveis e ambientalmente sustentáveis como matéria-prima para a produção de produtos de base biológica ganhou interesse recentemente. Para esse fim, a aplicação de um pré-tratamento adequado para melhorar a digestibilidade da biomassa e a otimização da hidrólise da biomassa para a produção de açúcares fermentáveis é crucial. A combinação de pré-tratamentos juntamente com o emprego de microrganismos tolerantes aos inibidores gerados durante o processo ou capazes de fermentar açúcares de pentose em hidrolisados mostraram ser abordagens interessantes (DIAZ; BLANDINO; CARO, 2018).

Atualmente, as técnicas de pré-tratamento disponíveis incluem explosão a vapor, moagem, explosão por congelamento, tratamentos químicos com ácidos, bases, solventes orgânicos ou outros produtos químicos e tratamento com fungos (DIAZ; BLANDINO; CARO, 2018).

Os processos de pré-tratamento podem ser físicos, químicos, biológicos ou uma combinação desses métodos. Os pré-tratamentos físicos geralmente consistem em reduzir o tamanho da biomassa ou a deformação da estrutura da biomassa, enquanto os pré-tratamentos químicos removem as barreiras químicas das enzimas. No que diz respeito aos pré-tratamentos 
biológicos, eles utilizam microrganismos para alcançar qualquer um dos resultados anteriores (DIAZ; BLANDINO; CARO, 2018).

Quanto a etapa de otimização por hidrólise, os resíduos agroindustriais podem ser hidrolizados para produzir açúcares fermentáveis, o que pode ser realizado por meio de produtos químicos, como ácidos (ácido sulfúrico, ácido clorídrico, etc.), líquidos iônicos ou enzimas (celulases, hemicelulases, pectinases, etc.). Cada método tem várias vantagens e desvantagens. Quanto ao primeiro, o tempo de retenção pode ser mais curto e os custos mais baixos, embora também apresente algumas desvantagens, incluindo a geração de compostos inibidores para a etapa subsequente de fermentação, necessidade de alta temperaturas e problemas de corrosão nos reatores. No caso da hidrólise enzimática, apesar do maior tempo de retenção e o alto custo das enzimas, pode-se operar em temperaturas mais baixas e faixas de $\mathrm{pH}$ mais baixas, evitando problemas de corrosão (KUMAR; SINGH; KORSTAD, 2017).

Embora os processos enzimáticos sejam preferidos aos químicos, o custo das enzimas é um fator limitante. Considera-se que cerca de 30 a $40 \%$ do custo em produção de enzimas é devido ao substrato da fermentação, o que poderia ser reduzido usando-se substratos de baixo custo, como os resíduos agroindustriais (MARZO et al., 2019).

\subsection{Fermentação em estado sólido (FES)}

A ampla diversidade de matérias primas encontradas nos resíduos agroindustriais, eles serem de fácil acesso e baixo custo, fazem desses resíduos ótimos candidatos para serem reaproveitados para a produção de um produto comercial. Nessa produção pode-se utilizar três métodos fermentativos: Fermentação Submersa, Fermentação em Superfície e Fermentação em Estado Sólido, sendo que cada um deles possui características peculiares no processo (BOSSA et al., 2019). No entanto, a fermentação em estado sólido (FES) possui grande potencial em comparação com os outros tipos de fermentação para a utilização dos resíduos agroindustriais na produção de biomoléculas, principalmente devido à natureza físico-química de muitos substratos lignocelulósicos que se prestam, naturalmente, para a fase sólida do cultivo (RAVINDRAN et al., 2018).

A FES é um bioprocesso no qual os microrganismos se desenvolvem em um ambiente sem água livre ou com um conteúdo muito baixo de água livre; é um tipo de fermentação heterogênea trifásica (sólido-líquido-gás), em que os microrganismos crescem na superfície de substrato sólido poroso com umidade suficiente para manter o crescimento e metabolismo microbiano. As partículas sólidas representam a fase principal e o processo é realizado na ausência ou quase ausência de água visível entre as partículas (DIAZ et al., 2016). Na maioria dos casos, os fungos filamentosos são escolhidos para processos de FES devido à sua exclusiva 
capacidade de colonizar os espaços interparticulares de matrizes sólidas e conseguir secretar várias enzimas para hidrolisar o substrato (Figura 2).

Figura 2. Esquema do crescimento fúngico na superfície de substratos sólidos.

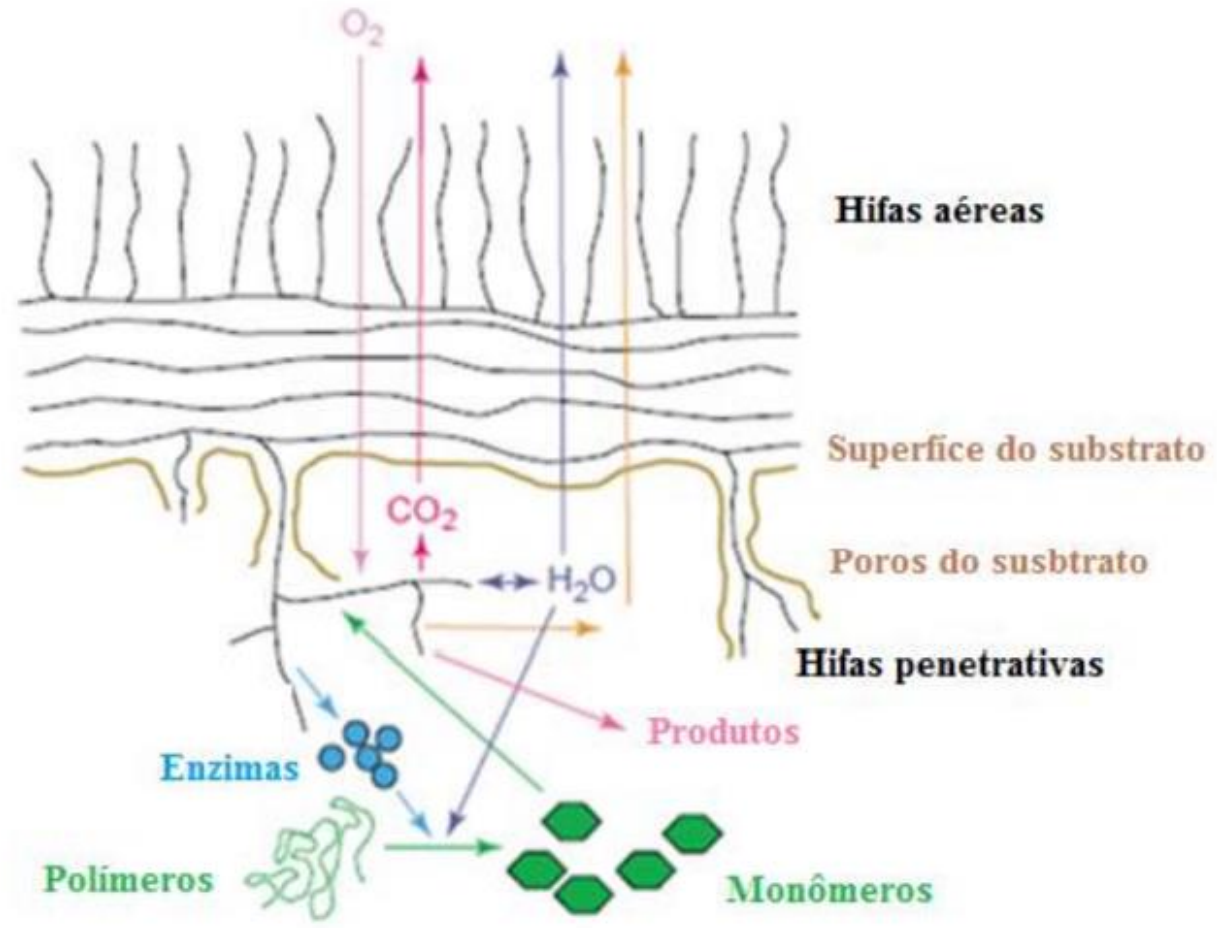

Fonte: HÖLKER; LENZ, 2005.

Considerando que o Brasil é um grande produtor agrícola e que há grande geração de resíduos, a FES se apresenta como uma alternativa bastante viável para o aproveitamento desses resíduos, gerando substâncias de interesse econômico, como enzimas, ácidos orgânicos, aromas e pigmentos, por exemplo. Sendo uma tecnologia que provou ser muito eficiente em termos de produtividade, baixo consumo de energia e resolução dos problemas de descarte. Portanto, essa tecnologia fornece uma alternativa de abordagem bastante econômica para exploração dos resíduos (BOSSA et al., 2019; MARZO et al., 2019).

Os resíduos agroindustriais são substratos interessantes para processos FES também por serem ricos em açúcares complexos, como celulose, hemicelulose e pectina, que podem ser convertidos em açúcares simples e assimilados pelos fungos, visto que o tipo de bioproduto formado vai depender muito das composição do substrato utilizado (MARZO et al., 2019). 


\subsection{Composição do meio de cultura}

Está bem documentado que diferentes microganismos diferem em sua eficiência na produção de biomoléculas, dependendo principalmente de sua capacidade de fermentação e de suas características nutricionais, fisiológicas e genéticas (DURAIKANNU; CHANDRASEKARAN, 2018). O desempenho do processo fermentativo é afetado por fatores químicos como $\mathrm{pH}$, fatores físicos como a temperatura, agitação e aeração e também pelos componentes do meio de cultivo, sendo os constituintes nutricionais dos resíduos agroinduatriais de suma importância nesse processo (BOSSA et al., 2019).

A composição do meio de fermentação, a concentração dos constituintes, o rendimento e a produtividade volumétrica desempenham papeis importantes na produção de metabólitos primários e secundários pelos microrganismos, influenciando na taxa de produção das biomoléculas. Atingir o objetivo industrial básico de produzir biomoléculas usando um microrganismo é possível quando a escolha desse microrganismo for baseada em sua capacidade de crescimento e no seu potencial de produção das moléculas de interesse, sendo que o parâmetro de constituição do meio de cultura desempenham um papel crucial nesse processo (DURAIKANNU; CHANDRASEKARAN, 2018). A Tabela 1 demonstra a composição de diversos tipos de resíduos agroindurstriais.

Tabela 1 - Composição química (\%) de resíduos importantes da agroindústria.

\begin{tabular}{lllllll}
\hline $\begin{array}{l}\text { Resíduo } \\
\text { agroindustrial }\end{array}$ & Carboidratos & $\begin{array}{l}\text { Fibras } \\
\text { brutas }\end{array}$ & Pectinas & Gorduras & Proteínas & Ligninas \\
\hline $\begin{array}{l}\text { Bagaço da cana-de- } \\
\text { açúcar }\end{array}$ & $66,48 \pm 2,68$ & - & - & - & 2,3 & $17,79 \pm 0,62$ \\
Farelo de arroz & $14,1 \pm 1,1$ & 26,9 & - & $30,4 \pm 0,9$ & $38,2 \pm 2,3$ & 25,63 \\
Farelo de trigo & 56,8 & $33,4-63,0$ & - & $3,5-3,9$ & $13,2-18,4$ & 5,6 \\
Borra de café & $55,53 \pm 0,85$ & $60,46 \pm 2,2$ & - & $2,29 \pm 0,30$ & $17,44 \pm$ & $23,90 \pm 0,30$ \\
& & & & & 0,10 & \\
Casca de mandioca & $75,5 \pm 1,2$ & $11,2 \pm 0,6$ & - & $3,1 \pm 0,1$ & $1,7 \pm 0,1$ & $1,92 \pm 0,07$ \\
Resíduo de maçãa & $48,0-62,0$ & - & - & - & $3,9-5,7$ & 23,5 \\
Resíduo de azeitona & $34,8 \pm 0,9$ & - & - & $16,65 \pm 0,09$ & $4 \pm 1,0$ & $43,2 \pm 0,5$ \\
Casca de banana & $79,0 \pm 0,5$ & $9,3 \pm 0,1$ & - & $3,0 \pm 0,2$ & $0,6 \pm 0,1$ & $6,4-9,6$ \\
Casca de laranja & 30 & - & 14,4 & - & 7,9 & 1,0 \\
\hline
\end{tabular}

Fonte: RAVINDRAN et al., 2018. 


\subsection{Microrganismos utilizados nos processos fermentativos}

No processo de fermentação, os microrganismos realizam uma série de reações catalisadas por enzimas para obtenção de energia através da degradação de moléculas complexas de açúcares em moléculas orgânicas mais simples como o ácido pirúvico, com produção de ATP (MOREIRA, 2015).

Neste processo para obtenção de energia, os microrganismos sintetizam metabólitos secundários, que são compostos extracelulares secretados no meio de cultura durante o crescimento e diferenciação de um organismo vivo, muitos desses metabólitos têm sido isolados e caracterizados, principalmente para fins industriais (SPECIAN et al., 2014).

Grande parte dos avanços nessa área são derivados das descobertas recentes nas áreas de genética, fisiologia e metabolismo de microrganismos. A diversidade genética e metabólica dos microrganismos tem sido explorada há muitos anos visando a obtenção de produtos biotecnológicos, tais como a produção de antibióticos (estreptomicina, penicilina, etc.), de alimentos (cogumelos), processamento de alimentos (queijo, iogurte, vinagre, etc.), bebidas alcoólicas (vinho, cerveja, etc.), ácidos orgânicos (cítrico e fumárico), álcoois (etanol), alimentos fermentados (molho de soja), tratamento e/ou remediação de resíduos (esgotos domésticos, lixo), e na agricultura, na fertilização de solos (fixação biológica de nitrogênio) e controle biológico de pragas e doenças (controle da lagarta da soja, da cigarrinha da cana de açúcar, de fitopatógenos como Rhizoctonia e outros) (FALEIRO, 2011). Exemplos de microrganismos utilizados em processos fermentativos para produção de bioprodutos são apresentados na Tabela 2.

Tabela 2 - Microrganismos utilizados em processos fermentativos para produção de bioprodutos.

\begin{tabular}{|l|l|}
\hline \multicolumn{1}{|c|}{ Microrganismos } & \multicolumn{1}{c|}{ Bioprodutos } \\
\hline Saccharomyces cerevisiae & Fermentação alcóolica em processos industriais \\
\hline $\begin{array}{l}\text { Lactobacillus fermentum; S. cerevisiae; S. uvarum; } \\
\text { Acetobacter aceti; } \text { Acetobacter orleanensis; }\end{array}$ & $\begin{array}{l}\text { Fermentação alcóolica na fabricação de vinho e } \\
\text { vinagre }\end{array}$ \\
\hline S. cerevisiae; S. uvarum & Produção de glicerol \\
\hline $\begin{array}{l}\text { Lactobacillus casei; } \text { L. acidophilus; } \text { L. plantarum. } \text { L. } \\
\text { fermentum }\end{array}$ & Produção de iogurtes \\
\hline Dunaliella bardawil & Síntese de $\beta$-caroteno \\
\hline Aspergillus spp. & $\alpha$-amilase, como detergente \\
\hline Bacillus subtilis & $\beta$-amilase, na produção de cerveja \\
\hline Tricoderma viride & Celulose \\
\hline S. cerevisiae & Invertase \\
\hline S. fragilis & Lactase \\
\hline Aspergillus niger & $\begin{array}{l}\text { Lipase, como detergente, na curtição de couro e } \\
\text { produção de queijo }\end{array}$ \\
\hline
\end{tabular}




\begin{tabular}{|l|l|}
\hline A. niger & Oxidades, no branqueamento de papel e tecido \\
\hline A. niger & Pectinases, em suco de frutas \\
\hline A. oryzae & $\begin{array}{l}\text { Proteases, como amaciante de carne, no auxílio } \\
\text { digestivo curtição de couro }\end{array}$ \\
\hline Mucor sp.; Escherichia coli & Renina, na produção de queijo \\
\hline Streptococcus $\beta$-hemolítico do grupo C & Estreptoquinase, utilizado na lise de coágulos \\
\hline Bacillus thuringiense & Biofertilizantes \\
\hline $\begin{array}{l}\text { Aspergillus fumigauts; Rhizopus stolonifer; } \\
\text { Rhodococcus sp.; Nocardia sp.; Bacillus sp.; } \\
\text { Pseudomonas sp. }\end{array}$ & $\begin{array}{l}\text { Degradação de moléculas químicas contidas em } \\
\text { defensivos agrícolas }\end{array}$ \\
\hline
\end{tabular}

Fonte: dos SANTOS et. al., 2018; PAMPHILE et. al., 2017; LIANG et. al., 2016; MARULANDA; GRANADOS; GARCÍA-ZAPATEIRO, 2016; MARTINEZ et. al., 2014; SAMUEL; LINA; IFEANYI, 2016; SANTOS et. al., 2009.

A chamada biologia sintética é aplicável em muitas áreas, transformando os microrganismos em fábricas para produzir moléculas de interesse. $\mathrm{O}$ seu potencial é imenso e as possibilidades de inovações são quase ilimitadas. Usando a biologia sintética, é possível transformar bactérias em veículos de produção de biomoléculas, projetar biomoléculas de acordo com alguma característica específica e controlar a produção de biomoléculas. Por exemplo, pode-se explorar bactérias como fábricas bioquímicas criando novas enzimas para produzir produtos químicos desejados; genomas bacterianos podem ser editados para tornar a célula bacteriana compatível com uma dada estratégia (FLORES BUESO; LEHOURITIS; TANGNEY, 2018).

Diversas espécies de microrganismos têm sido utilizadas na FES a partir de resíduos agroindustriais. Entretanto, os fungos possuem propriedades fisiológicas, bioquímicas e enzimáticas favoráveis à utilização na FES para produzir biomoléculas (BOSSA et al., 2019). Os fungos filamentosos são conhecidos por biossintetizar uma quantidade fantástica de metabólitos secundários, chegando a uma produção de até $73 \%$ superior a de outras classes de microrganismos (SPECIAN et al., 2014). Dentre os fungos que são preferencialmente utilizados para produção de produtos biotecnológicos, destacam-se algumas espécies dos gêneros Aspergillus e Penicillium (BOSSA et al., 2019).

Em segundo lugar, destacam-se as leveduras, que também são capazes de serem cultivadas em um ambiente de baixa atividade de água. Existe também o destaque de algumas espécies de bactérias (por exemplo, Bacillus subtilis, Bacillus thuringiensis e Lactobacillus sp.) e bactérias filamentosas (Streptomyces sp.) (SOCCOL et al., 2017). 


\subsection{Enzimas}

Ao selecionar o microrganismo correto, é possível obter, por fermentação dos açucares contidos nos resíduos agroindustriais, uma ampla gama de metabólitos que têm aplicações úteis (DIAZ; BLANDINO; CARO, 2018).

Dentre esses metabólicos estão as enzimas, que são biomoléculas conhecidas como catalisadores biológicos que encontram aplicações em diversas indústrias, variando desde indústrias de panificação e fabricação de cerveja, celulose para produção de papel, e indústria de detergente. Devido ao seu alto grau de especificidade de substrato e parâmetros operacionais rigorosos e robustos, o uso de enzimas é preferido à catálise química em muitas situações (RAVINDRAN et al., 2018).

Dentre as enzimas úteis em processos industriais, as celulases estão entre as principais enzimas extracelulares secretadas por diferentes tipos de fungos. As lipases e proteases fúngicas também têm grande importância na degradação microbiana de resíduos agroindustriais. As lipases (EC 3.1.1.3) catalisam a hidrólise de triacilgliceróis, principais constituintes de gorduras e óleos, amplamente encontrados em resíduos de origem vegetal. Os resultados dessa hidrólise são ácidos graxos livres, glicerol e acilgliceróis parciais, que são recursos energéticos facilmente utilizáveis pelos microrganismos (TAKÓ et al., 2015). As proteases microbianas pertencem ao grupo das hidrolases e são enzimas predominantemente multifuncionais que catalisam a lise de uma matriz de polímeros proteicos em constituinte peptídeos e aminoácidos. A contribuição global de proteases para enzimas industriais é de aproximadamente $60 \%$, dos quais as fontes primárias são bactérias do gênero Bacillus (NNOLIM; OKOH; NWODO, 2020).

As queratinases microbianas (EC 3.4.21 / 24 / 99.11), que também são membros das enzimas proteolíticas, é um grupo predominantemente associado a hidrólise de queratina (NNOLIM; OKOH; NWODO, 2020).

Com o advento da tecnologia de DNA recombinante, houve a possibilidade de clonar microrganismos e produzir em massa enzimas de qualquer origem para atender à demanda de várias indústrias. A melhoria das cepas por mutação é uma tecnologia amplamente empregada na indústria para aumentar o rendimento na produção de enzimas (RAVINDRAN; JAISWAL, 2016).

Espera-se que o mercado global de enzimas para uso industrial aumente a um crescimento anual de 4,7\% entre 2016 e 2021 (passando de aproximadamente 5 Bilhões de dólares americanos em 2016 para 6,3 Bilhões de dólares americanos em 2021). Entretanto, apesar da demanda crescente, as enzimas são reagentes relativamente caros, e isso aumenta o custo operacional dos processos que as utilizam. Uma análise crítica do processo de produção 
de enzimas revela que quase 50\% do custo de produção está associado ao investimento de capital, enquanto o custo das matérias-primas representa quase um terço desses custos, a substituição ou complementação de matérias-primas por fontes oriundas de resíduos agroindustriais pode resultar em uma redução significativa desses custos (RAVINDRAN et al., 2018).

\subsection{Discussão}

Nos últimos anos, tem havido um interesse crescente em pesquisas na reutilização de resíduos e subprodutos agroalimentares. Os resíduos das indústrias agrícola e de alimentos são produzidos em grandes quantidades e seu descarte pressupõe um importante problema. Além disso, dado que este tipo de matéria-prima não serve mais para fins alimentares e devido também ao seu baixo custo, existe um potencial enorme de sua utilização em processos economicamente competitivos e também ecológicos (BELLASIO et al., 2015; MARZO et al., 2019).

Nesse sentido, a Lei n 12.305/20102 instituiu a Política Nacional de Resíduos Sólidos, que obriga os municípios a criarem planos de gerenciamento desses resíduos em suas regiões, sendo que a prioridade é a não geração, a redução, a reutilização, a reciclagem, o tratamento dos resíduos sólidos e a disposição ambientalmente adequada dos rejeitos. Assim sendo, a reutilização desses resíduos para a produção de bioprodutos é de grande valia (RODRIGUES et al., 2013).

$\mathrm{Na}$ literatura encontramos diversos casos de aproveitamento dos resíduos agroindustriais para a produção de biomoléculas. Essas biomoléculas podem ser comercializadas como produtos finais, serem utilizadas para a produção de outros produtos de valor agregado ou serem utilizadas no processo de descarte ecológico dos resíduos produzidos pelas indústrias.

Cunha et al., 2016 avaliou a produção de enzimas amilolíticas, celulolíticas e proteolíticas pela linhagem Penicillium spp. LEMI A8221 cultivada por fermentação em estado sólido utilizando resíduos da colheita de soja (grãos pequenos e quebrados, vagens, hastes e folhas). A composição química geral dos resíduos da colheita de soja (50\% de celulose, $25 \%$ de hemicelulose e $25 \%$ de lignina), fazem desse tipo de resíduo um excelente substrato para o crescimento e desenvolvimento de microrganismos para promover a bioconversão da celulose e da lignina em produtos de interesse econômico. O Penicillium spp. LEMI A8221 foi considerado um agente biológico promissor para a aplicação industrial, especialmente para 
produção de protease, uma vez que o fungo apresentou eficiência satisfatória na conversão do substrato nos produtos de interesse.

Naidu; Siddiqui \& Idris, 2020, em sua pesquisa no país da Malásia, utilizaram fungos Himenomicetos, Pycnoporus sanguineus e Trametes lactinea, por fermentação em estado sólido para a biodegradação dos resíduos ligno-hemicelulolíticos produzidos a partir das indústrias de óleo de palma, sendo que o descarte dos resíduos gerados com a utilização dos dendezeiros é um grande desafio para esse ramo industrial, pois gera-se 80 milhões de toneladas de resíduos verdes / biomassa lignocelulósica, esses resíduos incluem: troncos de dendezeiros, folhas de dendezeiros, cacho de frutos vazios de óleo de palma, fibras prensadas de óleo de palma, e efluentes da moagem dos frutos.

Já Takó et al, 2015 produziu celulases, lipases e proteases a partir dos fungos Zigomicetos, Mucor corticolus, Rhizomucor miehei, Gilbertella persicaria e Rhizopus niveus usando resíduos agroindustriais como substratos para posterior produção de bioetanol. Vários Zigomicetos são conhecidos como fontes valiosas de substâncias extracelulares e hidrolases, algumas das quais podem ser empregadas em processos industriais. Utilizou-se a fermentação em estado sólido com resíduos de milho não tratados (caule e folha) e também com resíduos de milho e farelo de trigo. Os pesquisadores concluíram que os resíduos de caule e folhas de milho eram potencialmente aplicáveis como uma fonte com propriedades de forte indução na produção de celulase e lipase pelos fungos. As celulases produzidas eram então utilizadas para a conversão de biomassas de origem celulósica em etanol, sendo que para esse processo é necessário a hidrólise enzimática da biomassa em glicose fermentável. Essa degradação é realizada pelas celulases, que são misturas complexas de enzimas com diferentes especificidades para hidrolisar as ligações p-1,4-glicosídicas da celulose. A adição do coquetel de celulase aos resíduos celulósicos agilizou o processo de sacarificação e, portanto, a produção do bioetanol de forma eficaz e ecológica.

Nascimento et al., 2014 estudou uma seleção de 14 amostras de Aspergillus sp. isoladas do solo da Caatinga de Pernambuco, Brasil, para produção de tanase em meios alternativos contendo resíduos agroindustriais oriundos da indústria de sucos e bebidas (cascas de café, tangerina e uva). A tanase (EC 3.1.1.20) é uma esterase e depsidase formada predominantemente por ácido gálico, que possui inúmeras aplicações biotecnológicas. A enzima tanase faz parte de um dos maiores grupos de enzimas industriais descritas na literatura, pois hidrolisa ésteres e apresenta ligações laterais de taninos hidrolisáveis, produzindo, assim, glicose e ácido gálico. A tanase é uma enzima extracelular, produzida na presença de ácido tânico por fungos filamentosos, bactérias e leveduras. O gênero Aspergillus se destaca como 
um excelente produtor de tanase. Neste caso foi utilizada a fermentação submersa. O meio que continha resíduo de café apresentou maior produção de tanase, quando comparado ao meio controle e aos demais meios contendo os outros resíduos agroindustriais (laranja e uva). Verificou-se a habilidade do Aspergillus sp, de amostra isolada do solo da Caatinga, em hidrolisar os taninos presentes nos resíduos testados, transformando-os na enzima tanase.

Um outro estudo, proposto por Nnolim; Okoh \& Nwodo, 2020 avaliou os potenciais de produção de enzimas queratinolíticas de alguns isolados bacterianos autóctones no solo do município de Raymond Mhlaba, na África do Sul. Muitos setores agroindustriais acumulam biomassa de resíduos queratinosos que podem ser aproveitados para a produção de itens alto valor. Amostras de solo foram coletadas de lixões, de onde foram isoladas bactérias produtoras de queratinase. A atividade da queratinase foi avaliada em relação à formação de tiol e percentual de degradação de penas. A espécie Bacillus sp. isolada desses solos apresentou o melhor potencial queratinolítico, com maior atividade extracelular de queratinase e de degradação de penas, se revelando em um grande potencial para uso biotecnológico.

O estudo de Prakash et al. 2018 investigou a viabilidade de produção de bioetanol a partir de cascas de banana usando enzimas termo alcalina estáveis. Essas enzimas foram produzidas a partir de resíduos agroindustriais. Os pesquisadores isolaram o Geobacillus stearothermophilus HPA19 para produzir um coquetel de enzimas xilano-pectino-celulolítica termo-alcalina, usando outro tipo de resíduo, o farelo de trigo. O aproveitamento das cascas de banana para a produção de bioetanol é muito útil, uma vez que esses resíduos são geralmente jogados pelos cultivadores em cursos d'água ou em aterros sanitários locais, havendo um efeito prejudicial no meio ambiente.

\section{Considerações Finais}

As pesquisas no campo da utilização de resíduos agroindustriais são essenciais, não só pela problemática ambiental, mas também pela preferência do mercado por produtos naturais, biodegradáveis e ambientalmente amigáveis. A acessibilidade a fontes alternativas e economicamente viáveis de substratos para a produção fermentativa de produtos de alto valor agregado, como as biomoléculas é fundamental para o desenvolvimento da biotecnologia sustentável. 


\section{Referências}

BELLASIO, M. et al. Organic acids from lignocellulose: Candida lignohabitans as a new microbial cell factory. Journal of Industrial Microbiology and Biotechnology, v. 42, n. 5, p. 681-691, 2015.

BOSSA, L. F. et al. Resíduos agroindustriais para produção de produtos biotecnológicos. In: Agroecologia : caminho de preservação do meio ambiente. [s.l: s.n.]. p. 9-25, 2019.

CHANDEL, A. K.; SINGH, O. V. Weedy lignocellulosic feedstock and microbial metabolic engineering: Advancing the generation of "Biofuel". Applied Microbiology and Biotechnology, v. 89, n. 5, p. 1289-1303, 2011.

COSTA FILHO, D. V. et al. Aproveitamento de resíduos agroindustriais na elaboração de subprodutos. In: II Congresso Internacional das Ciências Agrárias COINTER-PDVAgro 2017. ISSN: 2526-7701.Oral. João Pessoa: Pernambuco, 2017, p. 1-8, 2017.

CUNHA, J. R. B. et al. Cultivo de Penicillium spp. em resíduos da colheita de soja para produção de celulase, protease e amilase. Rev. Ceres Viçosa, v. 63, n. 5, p. 597-504, 2016.

DIAZ, A. B. et al. Modelling of different enzyme productions by solid-state fermentation on several agro-industrial residues. Applied Microbiology and Biotechnology, v. 100, n. 22, p. 9555-9566, 2016.

DIAZ, A. B.; BLANDINO, A.; CARO, I. Value added products from fermentation of sugars derived from agro-food residues. Trends in Food Science and Technology, v. 71, p. 52-64, 2018.

dos SANTOS, P. S. et. al. Fermentação em estado sólido em resíduos agroindustriais para a produção de enzimas: uma revisão sistemática. The Journal of Engineering and Exact Sciences, v. 4, n. 2, 2018.

DURAIKANNU, D.; CHANDRASEKARAN, S. D. Optimization and modeling studies on the production of a new fibrinolytic protease using Streptomyces radiopugnans_VITSD8. Frontiers in Biology, v. 13, n. 1, p. 70-77, 2018.

FALEIRO, A. Biotecnologia: uma visão geral. In: Biotecnologia: estado da arte e aplicações na agropecuária. [s.l: s.n.], 2011.

FAO. Desperdício de alimentos tem consequências no clima, na água, na terra e na biodiversidade. Disponível em: http://www.fao.org.br/daccatb.asp. Acesso em: 20 de Julho de 2020.

FLORES BUESO, Y.; LEHOURITIS, P.; TANGNEY, M. In situ biomolecule production by bacteria; a synthetic biology approach to medicine. Journal of Controlled Release, v. 275, p. 217-228, 2018.

HÖLKER, U.; LENZ, J. Solid-state fermentation: are there any biotechnological advantages? Current Opinion in Microbiology, v. 8, n. 3, p. 301-306, 2005.

KUMAR, D.; SINGH, B.; KORSTAD, J. Utilization of lignocellulosic biomass by oleaginous yeast and bacteria for production of biodiesel and renewable diesel. Renewable and 
Sustainable Energy Reviews, v. 73, n. October 2015, p. 654-671, 2017.

LIANG, M-H et. al.. Inhibiting Lycopene Cyclases to Accumulate Lycopene in High $\beta$ Carotene-Accumulating Dunaliella bardawil. Food Bioprocess Technol. v. 9, n. 6, p. 1002 1009, 2016.

MAPA. Projeções do Agronegócio: Brasil 2017/18 a 2027/28 projeções de longo prazo: Ministério da Agricultura, Pecuária e Abastecimento. Secretaria de Política Agrícola. Brasília: MAPA/ACE. [s.l: s.n.].

MARTINEZ, M. E. M. et. al. Estudo da fermentação submersa não aerada por Saccharomyces cerevisiae para determinação dos parâmetros de consumo de glicose e produção de glicerol e etanol. Eclética Química. v. 39, p. 91-106, 2014.

MARULANDA, M.; GRANADOS, C.; GARCÍA-ZAPATEIRO, L. A. Análisis sensorial y estimación fisicoquímica de vida útil de una bebida tipo yogur a base de lactosuero dulce fermentada con Estreptococcus Salivarius ssp. Thermophilus y Lactobacillus Casei ssp. Casei. Producción + Limpia. v.11, n.1, p. 94-102, 2016.

MARZO, C. et al. Valorization of agro-industrial wastes to produce hydrolytic enzymes by fungal solid-state fermentation. Waste Management and Research, v. 37, n. 2, p. 149-156, 2019.

MOREIRA, C. Fermentação, Rev. Ciência Elem., v. 3 n. 2 p. 106, 2015.

NAIDU, Y.; SIDDIQUI, Y.; IDRIS, A. S. Comprehensive studies on optimization of lignohemicellulolytic enzymes by indigenous white rot hymenomycetes under solid-state cultivation using agro-industrial wastes. Journal of Environmental Management, v. 259, p. 110056, 2020.

NNOLIM, N. E.; OKOH, A. I.; NWODO, U. U. Proteolytic bacteria isolated from agro-waste dumpsites produced keratinolytic enzymes. Biotechnology Reports, v. 27, p. e00483, 2020.

NASCIMENTO, K. B. DE M. et al. Utilização de resíduos agroindustriais para produção de tanase por Aspergillus sp. isolado do solo da caatinga de Pernambuco, Brasil. E-Xacta, v. 1, n. 1, p. 95-103, 2014.

PAMPHILE et. al. Aplicações biotecnológicas de metabólitos secundários extraídos de fungos endofíticos: o caso do Colletotrichum sp. Revista Uningá, v. 53, n. 1, p. 113-119, 2017.

PANESAR, P.S., KAUR, R., SINGLA, G., SANGWAN, R.S. Bio-processing of agro-industrial wastes for production of food-grade enzymes: progress and prospects. Appl Food Biotechnol, v. 3, n. 4, p. 208-227, 2016.

PRAKASH, H. et al. Development of eco-friendly process for the production of bioethanol from banana peel using inhouse developed cocktail of thermo-alkali-stable depolymerizing enzymes. Bioprocess and Biosystems Engineering, v. 41, n. 7, p. 1003-1016, 2018.

RAVINDRAN, R. et al. A review on bioconversion of agro-industrial wastes to industrially important enzymes. Bioengineering, v. 5, n. 4, p. 1-20, 2018.

RAVINDRAN, R.; JAISWAL, A. K. Microbial enzyme production using lignocellulosic food 
industry wastes as feedstock: A review. Bioengineering, v. 3, n. 4, 2016.

RODRIGUES, L. S. et al. Gerenciamento de resíduos sólidos agrossilvipastoris e agroindustriais. Cadernos Técnicos de Veterinária e Zootecnia (Cadernos Técnicos da Escola de Veterinária da UFMG), n. 68, 2013.

SADH, P. K.; DUHAN, S.; DUHAN, J. S. Agro-industrial wastes and their utilization using solid state fermentation: a review. Bioresources and Bioprocessing, v. 5, n. 1, p. 1-15, 2018.

SAMUEL, O.; LINA, J. ; IFEANYI, O. Production of vinegar from oil-palm wine using Acetobacter aceti isolated from rotten banana fruits. Universal Journal of Biomedical Engineering. v. 4, n. 1, p. 1-5, 2016.

SANTOS, R. N.; ALVES, A. O.; SILVEIRA, B. Microrganismos de uso biotecnológico. JEPEX, 2009.

SCHALCHLI, H. et al. Production of ligninolytic enzymes and some diffusible antifungal compounds by white-rot fungi using potato solid wastes as the sole nutrient source. International Journal of Laboratory Hematology, v. 38, n. 1, p. 42-49, 2016.

SOCCOL, C. R.; COSTA, E. S. F.; LETTI, L. A. J.; KARP, S. G.; WOICIECHOWSKI, A. L.; SOUZA-VANDENBERGHE, L. P. Recent developments and innovations in solid state fermentation. Biotechnology Research and Innovation, v. 1, p 52-71, 2017.

SPECIAN, V. et al. Secondary metabolites produced by endophytic fungi of pharmaceutical interest. UNOPAR Cient Ciênc Biol Saúde, v. 16, n. 345, p. 345-351, 2014.

TAKÓ, M. et al. Enhanced production of industrial enzymes in Mucoromycotina fungi during solid-state fermentation of agricultural wastes/by-products. Acta Biologica Hungarica, v. 66, n. 3, p. 348-360, 2015. 